\title{
¿Por qué los artistas se interesan por los niños?
}

\author{
I. Carabaño Aguado \\ Servicio de Pediatría. Hospital Infanta Elena. Valdemoro, Madrid. España.
}

Desde tiempos muy remotos -estoy pensando en los años 6000-3000 a.C.los pintores se han interesado por la representación iconográfica del niño. ¿A qué se debe este interés? Pasemos a analizarlo.

El narcisismo del artista le lleva a querer ser el centro de atención y a anhelar perpetuarse en el tiempo. Si con su obra no alcanza la eternidad, la conseguirá a través de la figura del hijo. Ya lo escribió Miguel Hernández en su Nana al niño de dos años: "Ríe. Contigo venceré siempre al tiempo, que es mi enemigo"1. Ahí tenemos un puntal de fascinación. Gracias a los niños, los artistas cruzan el olvido y llegan a la cima de la perpetuidad histórica. Por otra parte, el niño es posibilidad, potencia pura, como el folio en blanco, como el lienzo vacío, como la piedra sin cincelar, como la partitura sin notas. El niño es un reto. $Y$ el narcisismo del artista disfruta con los retos. El artista, en desafío constante, se piensa creador de mundos.
O mejor: vive con la ilusión de aprender a reseñar su mundo, esa realidad emocional tan poco accesible, tan excesiva y distinta para el resto de los mortales. Parece un niño que busca una explicación constante a lo que ocurre dentro de sí. Esa explicación, si consigue encontrarla, será plasmada en trazos, notas, colores: lo que el poeta José Hierro llamaba "formas de locura envidiable"2. Y de tal modo, conseguirá que otros vean su mundo interior, y que lo llamen hermoso, bello, frágil, lo$\mathrm{co}$, genial.

Segundo condicionante: afectividad extrema. El artista tiene una sensibilidad muy especial, que tiende a la desmesura. Sobre ella han escrito ilustres, como Vallejo Nájera ${ }^{3}$. De forma menos sesuda, pero también acertada, los cantaores flamencos lo expresan bien: "Yo no sé por qué será./ Me duelen más que las mías,/ las penas de los demás". Esa afectividad, que es la misma que le permite amar intensamente (recordemos a grandes ex-

Iván Carabaño Aguado, carabano1975@hotmail.com 
pertos en la materia, como Paul Gaugin o Pablo Ruiz Picasso), les lleva a idolatrar a los niños, a protegerlos desde el torreón de sus lienzos. En los niños, además, los pintores descubren una gran cantidad de matices, desde los más trágicos (como en Munch o en Michelena) hasta los más deliciosamente lúdicos y jocosos (como en Murillo o en Francisco de Goya). Hay tantas maneras de ver a los niños que podríamos jugar con aquello decía Eugenio d’Ors sobre la relación de los pintores con las paredes blancas:

"Se dice pronto una pared blanca. Algunos pintores saben cuán rico en tonos es una cosa así. (...) Hay cimas color rosa en una pared blanca; hay abismos azules. Hay verticales rayas de oro. Hay verdores misteriosos y fugacísimos ${ }^{4 "}$.

Por tanto, para el artista los niños serán múltiples, multicolores, variadísimos.

Tercer condicionante: complejo de inferioridad. Si bien hay muchos artistas que quedan en evidencia por un aparente narcisismo (en este sentido, escritores de la talla de Francisco Umbral serían de lo más representativo), lo cierto es que bajo muchos de ellos subyace un soterrado complejo de inferioridad (en Umbral, sin ir más lejos, tal y como destapa canallescamente Anna Caballé en Francisco Umbral: el frío de una vida ${ }^{5}$ ). No olvidemos, por ejemplo, la habitual actitud crí- tica con que el artista se refiere a su propia obra. Hay muchos autores, como Santiago Gómez Valverde, que están deseando que se publiquen sus versos para poder olvidarse de ellos, pues saben de sobra que luchar contra ellos es vano e imposible. La tarea del artista es una lucha frustrante contra sí, contra la opinión de los demás y -tal y como se ha dichocontra el tiempo. El niño, desde una posición vulnerable de inocencia, no supondrá un elemento crítico para el artista. Al artista, dicho de otro modo, no le asustan ni le intimidan los niños, pues ante ellos ve la fortaleza que no tiene. Por eso le gusta representarlos.

Indudablemente, esta breve reflexión sobre la personalidad artística es una simplificación, pero una simplificación que se me antoja pertinente. Al lector se le vendrán a la cabeza, por ejemplo, personalidades fuertes, del tipo de la de Picasso o la de Miles Davis, que supieron fagocitar tendencias y acabar capitaneándolas; o auténticos huraños, como Pío Baroja; y qué decir de figuras frágiles y con vocación de pasar desapercibidas, como el pobre César Vallejo, que se vio a sí mismo muerto en medio de la lluvia de París. Pero las excepciones, excepciones son y sólo eso.

En este número, la Revista de Pediatría de Atención Primaria, en línea con la cre- 
ciente humanización de hospitales y centros de salud, inaugura una nueva sección titulada A la Pediatría desde el Arte, que comentará diversos cuadros en los que los niños son los protagonistas centrales. Esperamos que sea de vuestro agrado.

\section{Bibliografía}

1. Hernández M. Obra poética completa. Madrid: Alianza Editorial S.A.; 1992. p. 768.

2. Hierro J. Libro de las alucinaciones. Madrid: Ed. Cátedra; 1986. p. 15-16.
3. Vallejo Nájera JA. Locos egregios. Barcelona: Ed. Argos Vergara; 1982.

4. d'Ors E. Oceanografía del tedio. Barcelona: Ed. Tusquets; 1981. p. 79.

5. Caballé A. Francisco Umbral: el frío de una vida. Madrid: Ed. Espasa Calpe; 2005. 